Anthony R. Frattalone Robert D. Stevens

\title{
Intracranial pressure and its surrogates
}

Received: 3 March 2011

Accepted: 6 March 2011

Published online: 20 April 2011

(C) Copyright jointly held by Springer and ESICM 2011

This editorial refers to the article available at: doi:10.1007/s00134-011-2224-2.

A. R. Frattalone · R. D. Stevens

Department of Anesthesiology and Critical Care Medicine, Johns Hopkins University School of Medicine,

Baltimore, MD, USA

A. R. Frattalone · R. D. Stevens

Department of Neurology,

Johns Hopkins University School of Medicine,

Baltimore, MD, USA

\section{R. D. Stevens}

Department of Neurosurgery,

Johns Hopkins University School of Medicine,

Baltimore, MD, USA

\section{R. D. Stevens}

Department of Radiology,

Johns Hopkins University School of Medicine,

Baltimore, MD, USA

\section{R. D. Stevens (}

Division of Neurosciences Critical Care Medicine, Johns Hopkins Hospital, Meyer 8-140, 600 N Wolfe St,

Baltimore, MD 21287, USA

e-mail: rstevens@jhmi.edu

Tel.: +1-410-9557481

Fax: +1-410-6147903

Intracranial hypertension [intracranial pressure (ICP) $>20 \mathrm{mmHg}$ ] is a life-threatening complication seen in a significant proportion of patients following severe traumatic and nontraumatic brain insults [1-3]. Sustained elevations in ICP generally signal secondary injury processes such as cerebral edema, hemorrhage, hydrocephalus and ischemia, and as a consequence the management of ICP has become a keystone in neurocritical care. Especially in unresponsive patients when the diagnostic yield of physical examination is limited, temporal trends in ICP can help identify critical changes in intracranial compliance and responses to therapy. Many studies indicate an independent association between the magnitude and duration of ICP elevation and unfavorable outcomes following severe brain injury [2-4]. The difference of ICP and mean arterial pressure, cerebral perfusion pressure (CPP), is widely used to infer relationships between systemic circulatory function and cerebral blood flow. Many interventions in brain resuscitation, such as hyperosmolar therapy, sedation, controlled ventilation, and use of vasopressor or inotropic agents, are targeted to ICP and CPP goals. Current guidelines recommend ICP monitoring in patients with severe traumatic brain injury (TBI) who are comatose after resuscitation and who either have abnormalities on cranial computed tomography (CT) scan or meet at least two of the following three criteria: age $>40$ years; systolic blood pressure $<90 \mathrm{mmHg}$; or motor posturing [5].

The gold standard for measuring ICP is via devices placed inside the brain (intraventricular and intraparenchymal monitors). These devices are resource-intensive, carry small but significant risks of infection and hemorrhage, and in the case of intraparenchymal monitors are prone to drift with accuracy declining over time. Alternative methods have been proposed that noninvasively assess ICP through the measurement of a surrogate variable: these include neuroimaging (cranial CT and brain MRI), transcranial Doppler, tympanic membrane displacement, intraocular pressure, venous ophtalmodynanometry, and changes in the optic nerve sheath diameter (ONSD). In this issue of Intensive Care Medicine, Dubourg et al. [6] present a meta-analysis of studies 
in which transorbital ultrasonography of the ONSD was used to estimate ICP. This technique is based on the observation that the optic nerve is in anatomical continuity with the CSF of the subarachnoid space. Elevations in ICP will cause optic nerve sheath swelling, which can be expressed quantitatively as an increase in the ONSD. The authors included six studies with data on a total of 231 patients following TBI or intracranial hemorrhage, and wisely considered only reports in which the technique was validated against invasive ICP measurement. When studies were pooled, the technique had a sensitivity of $90 \%$, a specificity of $85 \%$, and an area under the receiveroperating characteristic curve of $94 \%$. Metaregression suggested that heterogeneity in diagnostic accuracy of studies was not significantly influenced by variance in study-specific characteristics.

Optic nerve ultrasonography is appealing because it is a non-invasive bedside test that has minimal risk and good intra- and interobserver reliability [7]. Dubourg et al. conclude that ONSD ultrasound could become a valuable complement to neuromonitoring techniques, potentially informing decisions about invasive ICP assessment and regarding transfer to specialized units. The technique might be of particular interest in situations when invasive ICP monitoring is contraindicated (e.g., because of coagulopathy) or when the expertise for invasive monitor placement is not immediately available. However, with a false-negative rate of $10 \%$, ONSD results should only be interpreted in conjunction with data from the history, neurologic examination and neuroimaging. The technique has not been validated in patients with ocular or optic nerve trauma or with underlying conditions that may alter optic nerve anatomy, e.g., brain tumors, neuroinflammatory and neurodegenerative disorders, Grave's disease, and diseases associated with infiltration of neural tissue. Moreover, ONSD is a diagnostic tool, not a continuous monitoring technique, providing an estimate of ICP at one point in time but failing to inform on the number and duration of intracranial hypertension episodes, which weigh so heavily in TBI outcomes [8].

Even if noninvasive surrogates of ICP were perfectly accurate and reliable, the interpretation and management of ICP are fraught with theoretical and practical limitations. The correlation between clinical deterioration and ICP is not a robust one: because the brain is anatomically compartmentalized, fatal herniation syndromes may occur without associated changes in ICP, for example, after posterior fossa hemorrhage or infarction. Studies conducted in TBI patients with parenchymal oxygen or microdialysis probes demonstrate that brain tissue hypoxia and metabolic distress can occur independently of ICP or CPP [9, 10], perhaps superseding the latter in terms of prognostic significance [11]. Evidence that cerebral pressure autoregulation is globally or regionally impaired following severe TBI means that ischemia can occur at apparently adequate CPP levels [12, 13]-a serious challenge to the current recommendation of a single CPP target in all patients [14]. It is notable that clinical outcome-based studies are mixed regarding the impact of ICP monitoring. While protocolized care of severe TBI including ICP monitoring has been reported as beneficial [15], studies suggest that ICP monitoring may be associated with increased mortality [16], greater therapeutic intensity and longer length of stay in the ICU [17]. In light of these caveats, there is sufficient equipoise for a randomized controlled trial to evaluate the effect of an ICP-based algorithm in severe brain injury, in a manner analogous to the way pulmonary artery catheter-guided therapy was tested in acute lung injury [18]. Yet, as demonstrated in a recent Cochrane review, such a trial has never been conducted [19].

In summary, transorbital optic nerve sheath ultrasound is a promising non-invasive method that yields valuable information on intracranial compliance in selected patients with severe TBI or intracerebral hemorrhage. There is a high degree of concordance with invasively measured ICP; however, broader implementation will require validation in larger studies. Results of the ongoing MOONSTRIP (Measurement of Optic Nerve Sheath diameter in Traumatic Raised Intracranial Pressure) trial, a prospective observational study enrolling close to 600 subjects following TBI, are likely to illuminate this question [20].

\section{Conflict of interest None.}

\section{References}

1. Citerio G, Gaini SM, Tomei G, Stocchetti N (2007) Management of 350 aneurysmal subarachnoid hemorrhages in 22 Italian neurosurgical centers. Intensive Care Med 33:1580-1586
2. Juul N, Morris GF, Marshall SB, Marshall LF (2000) Intracranial hypertension and cerebral perfusion pressure: influence on neurological deterioration and outcome in severe head injury. The Executive Committee of the International Selfotel Trial. J Neurosurg 92:1-6
3. Schwab S, Aschoff A, Spranger M, Albert F, Hacke W (1996) The value of intracranial pressure monitoring in acute hemispheric stroke. Neurology 47:393-398 
4. Heuschmann PU, Kolominsky-Rabas PL, Misselwitz B, Hermanek P, Leffmann C, Janzen RW, Rother J, Buecker-Nott HJ, Berger K (2004) Predictors of in-hospital mortality and attributable risks of death after ischemic stroke: the German Stroke Registers Study Group. Arch Intern Med 164:1761-1768

5. Bratton SL, Chestnut RM, Ghajar J, McConnell Hammond FF, Harris OA, Hartl R, Manley GT, Nemecek A, Newell DW, Rosenthal G, Schouten J, Shutter L, Timmons SD, Ullman JS, Videtta W, Wilberger JE, Wright DW (2007) Guidelines for the management of severe traumatic brain injury VI Indications for intracranial pressure monitoring. J Neurotrauma 24(Suppl 1):S37-S44

6. Dubourg J, Javouhey E, Geeraerts T, Messerer M, Kassai B (2011)

Ultrasonography of the optic nerve sheath diameter for raised intracranial pressure detection: a systematic review and meta-analysis. Intensive Care Med. doi:10.1007/s00134-011-2224-2

7. Bäuerle J, Lochner P, Kaps M, Nedelmann M (2010) Intra- and interobsever reliability of sonographic assessment of the optic nerve sheath diameter in healthy adults. $\mathbf{J}$

Neuroimaging, pp 1-4. doi: 10.1111/j.1552-6569.2010.00546.x

8. Vik A, Nag T, Fredriksli OA, Skandsen T, Moen KG, Schirmer-Mikalsen K, Manley GT (2008) Relationship of "dose" of intracranial hypertension to outcome in severe traumatic brain injury. J Neurosurg 109:678-684

9. Chang JJ, Youn TS, Benson D, Mattick $\mathrm{H}$, Andrade N, Harper CR, Moore CB, Madden CJ, Diaz-Arrastia RR (2009) Physiologic and functional outcome correlates of brain tissue hypoxia in traumatic brain injury. Crit Care Med 37:283-290
10. Vespa PM, O'Phelan K, McArthur D, Miller C, Eliseo M, Hirt D, Glenn T, Hovda DA (2007) Pericontusional brain tissue exhibits persistent elevation of lactate/pyruvate ratio independent of cerebral perfusion pressure. Crit Care Med 35:1153-1160

11. Timofeev I, Carpenter KL, Nortje J, AlRawi PG, O'Connell MT, Czosnyka M, Smielewski P, Pickard JD, Menon DK, Kirkpatrick PJ, Gupta AK, Hutchinson PJ (2011) Cerebral extracellular chemistry and outcome following traumatic brain injury: a microdialysis study of 223 patients. Brain 134:484-494

12. Czosnyka M, Smielewski P, Piechnik S, Steiner LA, Pickard JD (2001) Cerebral autoregulation following head injury. J Neurosurg 95:756-763

13. Coles JP, Fryer TD, Smielewski P, Chatfield DA, Steiner LA, Johnston AJ, Downey SP, Williams GB, Aigbirhio F, Hutchinson PJ, Rice K, Carpenter TA, Clark JC, Pickard JD, Menon DK (2004) Incidence and mechanisms of cerebral ischemia in early clinical head injury. J Cereb Blood Flow Metab 24:202-211

14. Bratton SL, Chestnut RM, Ghajar J, McConnell Hammond FF, Harris OA, Hartl R, Manley GT, Nemecek A, Newell DW, Rosenthal G, Schouten J, Shutter L, Timmons SD, Ullman JS, Videtta W, Wilberger JE, Wright DW (2007) Guidelines for the management of severe traumatic brain injury. VIII. Intracranial pressure thresholds. J Neurotrauma 24(1):S55-S58
15. Bulger EM, Nathens AB, Rivara FP, Moore M, MacKenzie EJ, Jurkovich GJ (2002) Management of severe head injury: institutional variations in care and effect on outcome. Crit Care Med 30:1870-1876

16. Shafi S, Diaz-Arrastia R, Madden C, Gentilello L (2008) Intracranial pressure monitoring in brain-injured patients is associated with worsening of survival. J Trauma 64:335-340

17. Cremer OL, van Dijk GW, van Wensen E, Brekelmans GJ, Moons KG, Leenen LP, Kalkman CJ (2005) Effect of intracranial pressure monitoring and targeted intensive care on functional outcome after severe head injury. Crit Care Med 33:2207-2213

18. Heresi GA, Arroliga AC, Wiedemann HP, Matthay MA (2006) Pulmonary artery catheter and fluid management in acute lung injury and the acute respiratory distress syndrome. Clin Chest Med 27:627-635 abstract ix

19. Forsyth RJ, Wolny S, Rodrigues B (2010) Routine intracranial pressure monitoring in acute coma. Cochrane Database Syst Rev (2):CD002043

20. Sne N Measurement of optic nerve sheath diameter in traumatic raised intracranial pressure. http://clinicaltrials.gov/ct2/show/ NCT00783809 